\title{
Growth inhibition of Clostridium cellulolyticum by an inefficiently regulated carbon flow
}

\author{
E. Guedon, M. Desvaux, S. Payot and H. Petitdemange
}

Author for correspondence: H. Petitdemange. Tel: +33 383912053 . Fax : +33383912550. e-mail: hpetitde(a) lcb.u-nancy.fr

Laboratoire de Biochimie des Bactéries Gram +, Domaine Scientifique Victor Grignard, Université Henri Poincaré, Faculté des Sciences, BP 239, 54506 Vandœuvre-lès-Nancy Cédex, France

\begin{abstract}
Carbon flow in Clostridium cellulolyticum was investigated either in batch or continuous culture using a synthetic medium with cellobiose as the sole source of carbon and energy. Previous experiments carried out using a complex growth medium led to the conclusion that the carbon flow was stopped by intracellular NADH. In this study, results showed that cells cultured in a synthetic medium were better able to control electron flow since the NADH/NAD+ ratios were in the range 0.3-0.7, whereas a ratio as high as 57 was previously found in cells cultured on a complex medium. Furthermore, a specific rate of cellobiose consumption of $\left.2.13 \mathrm{mmol}^{(\mathrm{g} \text { cells) }}\right)^{-1} \mathrm{~h}^{-1}$ was observed on synthetic medium whereas the highest value obtained on complex medium was $0.68 \mathrm{mmol}\left(\mathrm{g}\right.$ cells) ${ }^{-1} \mathrm{~h}^{-1}$. When C. cellulolyticum was grown in continuous culture and cellobiose in the feed medium was increased from 5.84 to $17.57 \mathrm{mM}$ in stepwise fashion, there was an increase in cellobiose utilization without growth inhibition. In contrast, when the reactor was fed directly with $14.62 \mathrm{mM}$ cellobiose, residual cellobiose was observed (4.24 $\mathrm{mM}$ ) and growth was limited. These data indicate that $C$. cellulolyticum is not able to optimize its growth and carbon flow in response to a sudden increase in the concentration of growth substrate cellobiose. This interpretation was confirmed (i) by the study of cellobiose batch fermentation where it was demonstrated that growth inhibition was not due to nutritional limitation or inhibition by fermentation products but was associated with carbon excess and (ii) by the growth of C. cellulolyticum in dialysis culture where no growth inhibition was observed due to the limitation of carbon flow by the low rate of cellobiose diffusion through the dialysis tubing.
\end{abstract}

Keywords: Clostridium cellulolyticum, growth inhibition, synthetic medium, carbon flow

\section{INTRODUCTION}

Clostridium cellulolyticum was previously found to undergo an early growth stoppage when grown in batch cultures on cellobiose (Giallo et al., 1983). Giallo and coworkers reported that this inhibition was neither the result of nutrient depletion, nor the result of low $\mathrm{pH}$ or inhibition by end products; nevertheless, complex media were used routinely (Giallo et al., 1983; Gelhaye et al., 1993a, b; Gehin et al., 1995). From a fundamental point of view and to achieve biotechnological application, it is essential to understand the conditions that direct the increase of the bacterial population since cellulolytic

Abbreviations: $f d$, ferredoxin; O/R, oxidation/reduction. clostridia are of major importance in the anaerobic digestion of lignocellulose (Leschine, 1995).

Payot et al. (1998) demonstrated that, on complex media, the main product of C. cellulolyticum cellobiose catabolism was acetate, whereas the production of reduced compounds such as ethanol or lactate was low. Such patterns of product formation were accompanied by an accumulation of intracellular NADH leading to an $\mathrm{NADH} / \mathrm{NAD}^{+}$ratio as high as 57 (Payot et al., 1998). The high values of the NADH/NAD ${ }^{+}$ratio inhibited glyceraldehyde-3-phosphate dehydrogenase (GAPDH) activity which in turn limited cellobiose catabolism and cell growth. It is difficult to understand why during the course of C. cellulolyticum evolution such metabolic regulations have been selected. Taking into account that 
many natural ecosystems rarely contain all nutrients in high quantity (Koch, 1997), the aim of the present work was to study the behaviour of C. cellulolyticum on a synthetic medium with special attention to the effect of carbon flow on growth.

\section{METHODS}

Organism and medium. The organism used in this study was C. cellulolyticum ATCC 35319 , originally isolated by Petitdemange et al. (1984) from decayed grass. Stock cultures of C. cellulolyticum were maintained on cellulose as described previously (Payot et al., 1998) and were grown for one transfer on cellobiose before the initiation of growth experiments. The anaerobic culture technique used was that proposed by Hungate (1969) as modified by Bryant (1972).

The defined medium used in all experiments was a modification of the CM3 medium described by Weimer \& Zeikus (1977) in which $5 \mathrm{~g}$ yeast extract $\mathrm{I}^{-1}$ is replaced by oligoelement and vitamin solutions. The composition was $\left(\mathrm{g}^{-1}\right): \mathrm{KH}_{2} \mathrm{PO}_{4}$, $1.40 ; \mathrm{K}_{2} \mathrm{HPO}_{4} .3 \mathrm{H}_{2} \mathrm{O}, 2 \cdot 90 ;\left(\mathrm{NH}_{4}\right)_{2} \mathrm{SO}_{4}, 1.00 ; \mathrm{MgCl}_{2} \cdot 6 \mathrm{H}_{2} \mathrm{O}$, $0 \cdot 10 ; \mathrm{CaCl}_{2}, 0.02 ; 5 \%(\mathrm{w} / \mathrm{v}) \mathrm{FeSO}_{4}$ in $50 \mathrm{mM} \mathrm{H}_{2} \mathrm{SO}_{4}, 25 \mu \mathrm{l}$; trace element solution, $1.0 \mathrm{ml}$; vitamin solution, $10 \mathrm{ml} ; \mathrm{Na}_{2} \mathrm{~S}$, 0.50 and $0.2 \%(\mathrm{w} / \mathrm{v})$ resazurin, $0.5 \mathrm{ml}$. In addition, the medium contained cellobiose in variable amounts as specified in Results. The trace element solution contained $\left(\mathrm{g} \mathrm{l}^{-1}\right)$ : $\mathrm{FeSO}_{4} .7 \mathrm{H}_{2} \mathrm{O}, 5 \cdot 00 ; \mathrm{ZnSO}_{4} .7 \mathrm{H}_{2} \mathrm{O}, 1 \cdot 44 ; \mathrm{MnSO}_{4} \cdot 7 \mathrm{H}_{2} \mathrm{O}, 1 \cdot 12$; $\mathrm{CuSO}_{4} .5 \mathrm{H}_{2} \mathrm{O}, 0 \cdot 25 ; \mathrm{Na}_{2} \mathrm{~B}_{4} \mathrm{O}_{7}, 0 \cdot 20 ;(\mathrm{Mo})_{7}\left(\mathrm{NH}_{4}\right)_{6} \mathrm{O}_{24} \cdot 4 \mathrm{H}_{2} \mathrm{O}$, $1 \cdot 00 ; \mathrm{NiCl}_{2}, 0.04 ; \mathrm{CoCl}_{2}, 0 \cdot 02 ; \mathrm{HBO}_{3}, 0.03 ; \mathrm{Na}_{2} \mathrm{SeO}_{3}, 0 \cdot 02$; $\mathrm{HCl} 10 \mathrm{M}, 50.0 \mathrm{ml}$. The composition of the vitamin solution was $\left[\mathrm{mg}(100 \mathrm{ml} \text { distilled water })^{-1}\right]$ : D-biotin, $10 ; p$-aminobenzoic acid, 25 ; nicotinic acid, 15 ; riboflavin, 25 ; pantothenic acid, 25 ; thiamin, 25 ; cyanocobalamin, 10 . The vitamin solution was sterilized by filtration with a $0.2 \mu \mathrm{m}$ filter (Millipore).

Growth conditions. C. cellulolyticum was grown either in batch or in continuous culture. Cells were cultured aseptically in a 21 bioreactor (LSL BioLafitte) with a 1.51 working volume. Vitamin and trace element solutions, cellobiose and $\mathrm{Na}_{2} \mathrm{~S}$ were sequentially added to the medium for optimal reduction. Anoxic conditions were maintained by passing a stream of filter-sterilized nitrogen gas over the cultures. All tubing used was made of Viton (Du Pont) to prevent oxygen entry.

The temperature was maintained at $34^{\circ} \mathrm{C}$ and the $\mathrm{pH}$ was controlled at $7 \cdot 2$ by automatic additions of $1 \mathrm{M} \mathrm{NaOH}$. Agitation was kept constant at 50 r.p.m. For continuous fermentations, the volume was kept constant at 1.51 by automatic regulation of the culture level. The inoculum was $10 \%$ by volume and was in exponential-growth phase. The culture was grown in batches for $15 \mathrm{~h}$ before the medium flow was started. A period of three to four residence times was found to be sufficient to achieve steady-state values of the biomass and of the residual cellobiose concentration.

In addition, dialysis cultures were grown in 31 flasks and fermentations carried out in dialysis tubing (Visking, molecular mass cut-off 6000-8000 Da) as described previously (Gehin et al., 1996). No alteration of the tubing was observed during the course of our experiments.

Analytical procedures. Bacterial growth was measured spectrophotometrically at $600 \mathrm{~nm}$ and calibrated against cell dry weight measurement. Samples $(30 \mathrm{ml})$ were centrifuged $\left(8000 \mathrm{~g}, 10 \mathrm{~min}, 4^{\circ} \mathrm{C}\right)$, washed twice with $0.9 \%(\mathrm{w} / \mathrm{v}) \mathrm{NaCl}$ and dried at $65^{\circ} \mathrm{C}$ to constant weight $(48 \mathrm{~h})$. A mean biomass formula of $\mathrm{C}_{4} \mathrm{H}_{7} \mathrm{O}_{2} \mathrm{~N}$ and $\mathrm{C}_{16} \mathrm{H}_{25} \mathrm{O}_{9} \mathrm{~N}_{6}$ for extracellular proteins determined by elemental analysis (Service Central d'Analyses, CNRS), were used for elemental recovery calculations.

Culture supernatants $\left(10000 \mathrm{~g}, 15 \mathrm{~min}, 4^{\circ} \mathrm{C}\right)$ were stored at $-80^{\circ} \mathrm{C}$ until they were analysed. Cellobiose concentrations were determined by the method of Miller (1959). Acetate, lactate and ethanol were estimated by using the appropriate enzyme kits (Boehringer Mannheim). The fermenter effluent gas was measured by gas chromatography as described by Vasconcelos et al. (1994).

Extracellular proteins from the cell-free supernatant were measured by the Bradford dye method (Bradford, 1976). The quantity of amino acids present in the supernatant was measured using the procedure of Mokrasch (1967) and by ionexchange chromatography on a cation-exchange resin with a Beckman 7300 amino acid analyser. The mean elemental amino acid composition was $\mathrm{C}_{5} \mathrm{H}_{10} \mathrm{O}_{2 ;} \mathrm{N}$.

Extracellular pyruvate was quantitatively assayed using an enzymic method coupled with fluorimetric detection of NADH. Emission was measured at $459 \mathrm{~nm}$ after excitation at $341 \mathrm{~nm}$ with a fluorimeter (Hitachi F2000). The mixture contained triethanolamine buffer $(0.1 \mathrm{M}, \mathrm{pH} 7 \cdot 6), \mathrm{NADH}$ $(12.5 \mu \mathrm{M})$ and lactate dehydrogenase $(10 \mathrm{U})$.

Enzymic determination of intracellular pyruvate was not possible due to significant interference by extracellular pyruvate which led to erroneous estimates of intracellular concentrations.

Levels of $\mathrm{NAD}(\mathrm{P})^{+}$and $\mathrm{NAD}(\mathrm{P}) \mathrm{H}$ in the biomass were measured by first extracting the nucleotides from a sample of culture. $\mathrm{NAD}(\mathrm{P})^{+}$and $\mathrm{NAD}(\mathrm{P}) \mathrm{H}$ were extracted with $\mathrm{HCl}$ and $\mathrm{KOH}$, respectively, as described by Wimpenny \& Firth (1972). Levels of coenzymes in both extracts were determined by fluorimetric measurements. $\mathrm{NAD}^{+}$was assayed with a $\operatorname{NAD}(\mathrm{H})$-specific alcohol dehydrogenase (EC 1.1.1.1) and NADP $^{+}$was assayed with a glucose-6-phosphate dehydrogenase (EC 1.1.1.49) (Klingenberg, 1965; London \& Knight, 1966). NADH was determined using a lactate dehydrogenase (EC 1.1.1.27) assay (Klingenberg, 1965). NADPH was measured in a reaction mixture containing $100 \mathrm{mM}$ triethanolamine buffer ( $\mathrm{pH} 6.0), 20 \mathrm{mM} x$-ketoglutaric acid and $20 \mathrm{U}$ of NADP $(\mathrm{H})$-specific glutamate dehydrogenase from Proteus species (EC 1.4.1.4).

Calculations. The main products of cellobiose fermentation by C. cellulolyticum are acetate, ethanol, lactate, $\mathrm{H}_{2}$ and $\mathrm{CO}_{2}$ (Giallo et al., 1983). The reactions leading to the formation of the metabolites were described previously (Payot et al., 1998).

$q_{\text {cellotiose }}$ is the specific rate of cellobiose used in mmol ( $\mathrm{g}$ cells $)^{-1} \mathrm{~h}^{-1} ; q_{\text {acetate }}, q_{\text {ethanol }}$ and $q_{\text {lactate }}$ are the specific rates of product formation in mmol (g cells $)^{-1} \mathrm{~h}^{-1}$; and extracellular $q_{\text {pyruvate }}$ is the specific rate of extracellular pyruvate formation in $\mu \mathrm{mol}(\mathrm{g} \text { cells })^{-1} \mathrm{~h}^{-1}$.

The specific rates of NADH production and NADH consumption were calculated as described previously (Payot et al., 1998).

The specific rate of $\mathrm{H}_{2}$ production via the $\mathrm{NADH}$-ferredoxin (fd) $-\mathrm{H}_{2}$ path was calculated as follows:

$q_{\mathrm{NADH} \text { A }}=q_{\mathrm{NADH}}$ produced $-q_{\mathrm{NADH}}$ used

The oxidation/reduction $(O / R)$ index was calculated according to Gottschalk (1985). 
$Y_{\mathrm{ATp}}$, the energetic yield of biomass, can be calculated from acetate, lactate and ethanol concentrations according to equations described previously (Payot et al., 1998).

$$
\begin{array}{r}
Y_{\mathrm{ATP}}=\text { biomass concn } /(2 \text { concn } \\
\text { aretate } \\
+ \text { concn lartate } \\
\left.+ \text { concn }_{\text {ethanol }}\right)
\end{array}
$$

$Y_{\mathrm{ATP}}$ is in g cells (mol ATP) $)^{-1}$ produced.

$Y_{\mathrm{X} / \mathrm{s}}$, the molar growth yield for cellobiose, is in $\mathrm{g}$ cells (mol cellobiose $)^{-1}$ used.

Carbon recoveries were calculated from the production of biomass, fermentation products, amino acids and extracellular proteins present in the supernatant.

\section{RESULTS}

\section{Kinetic analysis of batch cellobiose fermentation}

When C. cellulolyticum was grown in batch culture on a defined medium with $23.4 \mathrm{mM}$ cellobiose as an energy source, the growth curve (Fig. 1a) was characterized by a maximum specific growth rate of $0 \cdot 18 \mathrm{~h}^{-1}$ (Fig. 2a). During the first $10 \mathrm{~h}$ after inoculation, growth and cellobiose consumption rates accelerated (Fig. 2a) and the cells produced acetate, ethanol and pyruvate (Fig. 1b). Accelerating growth was correlated with increasing

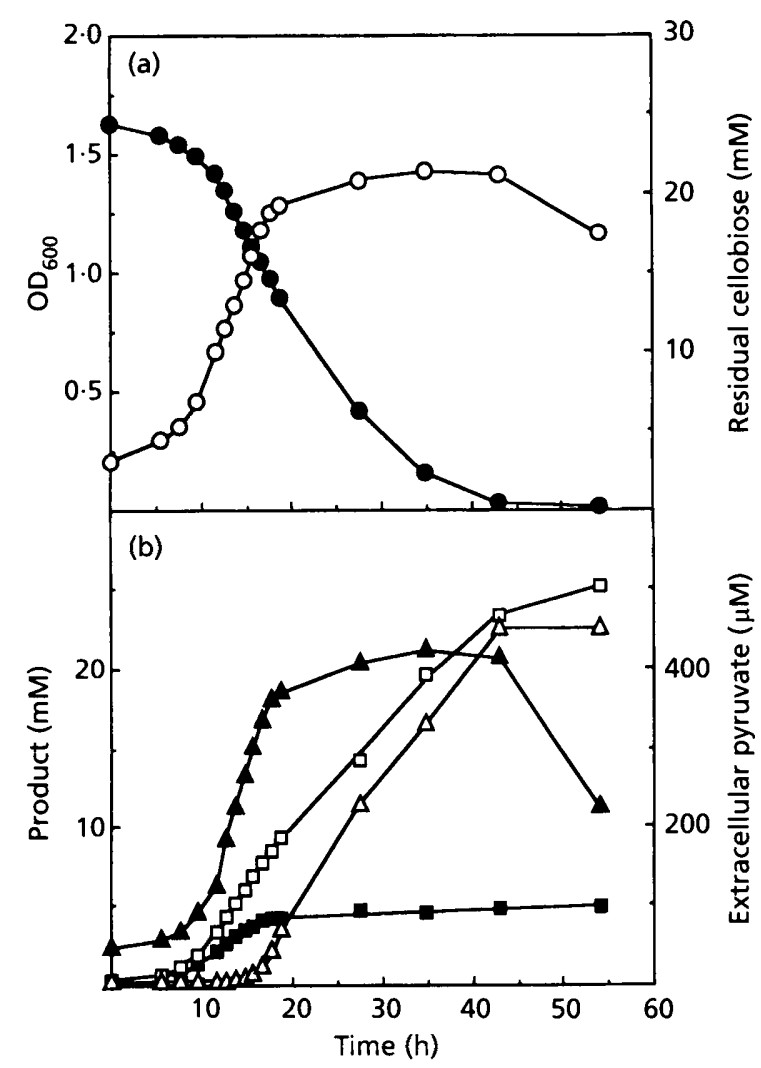

Fig. 1. Growth and cellobiose concentration (a) and product concentrations (b) during batch fermentation of $C$. cellulolyticum. The cellobiose concentration was $23.4 \mathrm{mM}$; ammonium concentration $(26.5 \mathrm{mM})$ was always in excess. $O$, Biomass; 0 , cellobiose; $\square$, acetate; $\triangle$, lactate; $\boldsymbol{\square}$, ethanol; $\boldsymbol{\Delta}$, extracellular pyruvate.

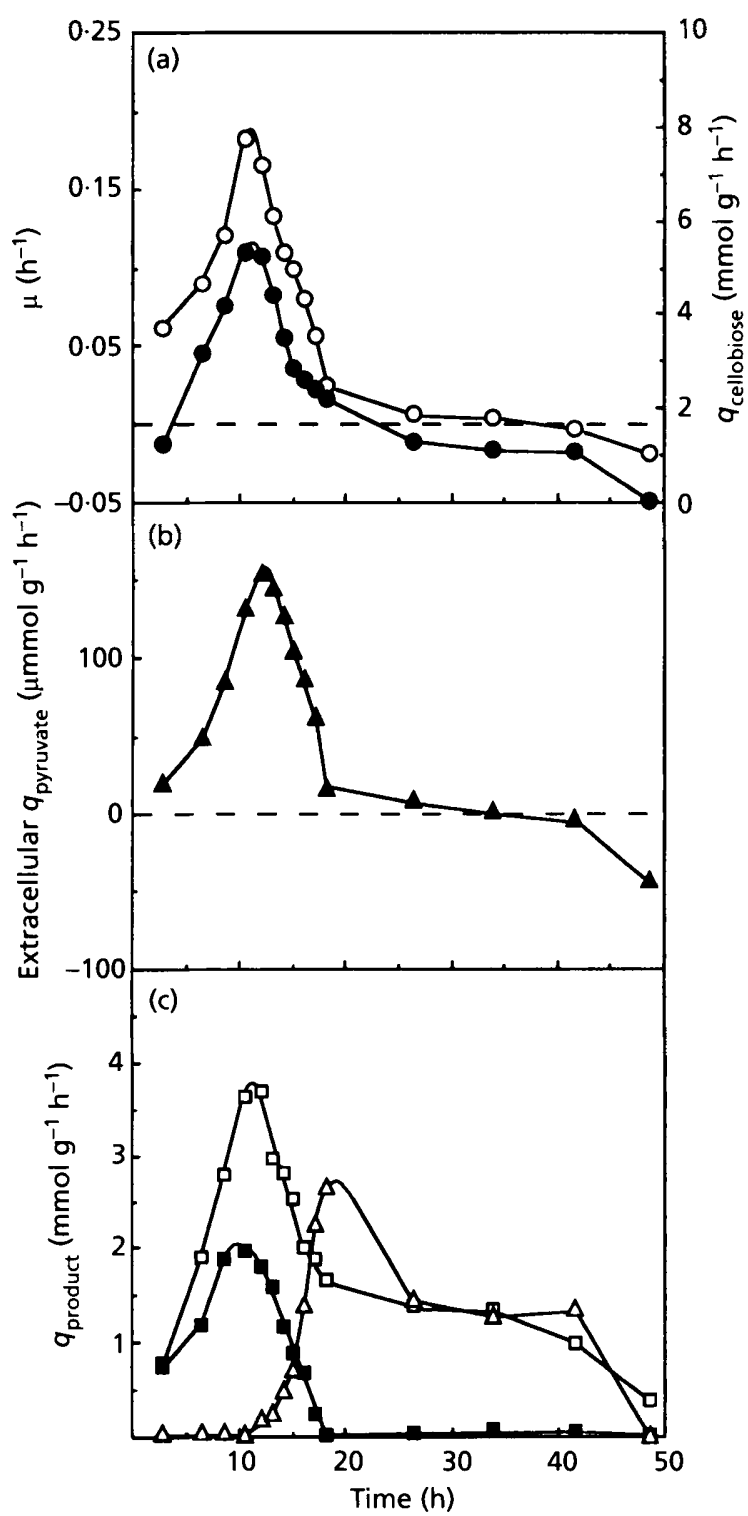

Fig. 2. Specific rates of growth and cellobiose consumption (a) and product formation $(b, c)$ during batch fermentation of $C$. cellulolyticum. The cellobiose concentration was $23.4 \mathrm{mM}$; ammonium concentration was always in excess. $O$, Specific growth rate; $\boldsymbol{\theta}$, specific rate of cellobiose consumption; $\boldsymbol{\Delta}, \square$, $\triangle, \boldsymbol{0}$, specific rates of extracellular pyruvate, acetate, lactate and ethanol formation, respectively.

production of extracellular pyruvate (Fig. 2b), acetate and ethanol (Fig. 2c) and was followed abruptly by a decelerating growth phase (Fig. 2a). The start of lactate formation (Fig. 2c) was associated with the peak of extracellular pyruvate production and the increase in the specific rate of lactate production corresponded to the decrease in pyruvate, acetate and ethanol biosynthesis (Fig. $2 \mathrm{~b}, \mathrm{c}$ ). Between 25 and $43 \mathrm{~h}$, the $q_{\text {lactate }}$ was stable and coincided with an almost nil pyruvate production (Fig. 2b, c). Growth ceased before the cellobiose was depleted (Fig. 1a), but cells continued to catabolize cellobiose and produce acetate and lactate. 
Table 1. Substrate, biomass and product concentrations and yields for continuous cultures of $C$. cellulolyticum

During all experiments, ammonium concentration was always in excess. For experiments $\mathrm{A}-\mathrm{H}_{1}$, cultures were provided with cellobiose in increasing amounts from 5.84 to $20.46 \mathrm{mM}$ (see Fig. 3 legend). In the experiments S, the reactor was fed directly with $14.62 \mathrm{mM}$ cellobiose. Values represent mean determinations from three different samples $( \pm \mathrm{sD})$. All other values were determined with a mean accuracy of $10 \%$.

\begin{tabular}{|c|c|c|c|c|c|c|c|c|c|c|c|}
\hline \multirow[t]{2}{*}{ Experiments } & \multirow[t]{2}{*}{$\begin{array}{c}D \\
\left(h^{\prime}\right)\end{array}$} & \multirow[t]{2}{*}{$\begin{array}{l}\text { Feed } \\
\text { cellobiose } \\
(\mathbf{m M})\end{array}$} & \multirow[t]{2}{*}{$\begin{array}{c}\text { Residual } \\
\text { cellobiose } \\
\quad(\mathbf{m M})\end{array}$} & \multirow[t]{2}{*}{$\begin{array}{c}\text { Biomass } \\
\left(\mathrm{g} \mathrm{I}^{1}\right)\end{array}$} & \multicolumn{3}{|c|}{$\begin{array}{l}\text { Product yield |mol } \\
\text { (mol cellobiose) '] }\end{array}$} & \multirow[t]{2}{*}{$\begin{array}{c}\text { Extracellular } \\
\text { pyruvate } \\
\langle\mu \mathrm{M})\end{array}$} & \multirow[t]{2}{*}{$\begin{array}{c}\text { Extracellular } \\
\text { protein } \\
\left(\mathbf{m g} \mathbf{1}^{1}\right)\end{array}$} & \multirow[t]{2}{*}{$\begin{array}{c}\text { Amino } \\
\text { acids } \\
(\mathrm{mM})\end{array}$} & \multirow[t]{2}{*}{$\begin{array}{c}\text { Carbon } \\
\text { recovery } \\
(\%)\end{array}$} \\
\hline & & & & & Acetate & Lactate & Ethanol & & & & \\
\hline$-\quad-\quad-$ & $-\quad-$ & $-\quad-\quad-$ & $-\cdots-$ & --- & --- & --- & -- & $-\cdots$ & $-\cdots-$ & --- & $--\cdots$ \\
\hline$A$ & 0.086 & ist & $0 \cdot 12 \pm(1 \cdot 0)=$ & $0.332 \pm 0.015$ & 1.68 & (0.10) & 0.53 & $149.2 \pm 8 \cdot 2$ & $289 \pm 1 \cdot 1$ & $(1.56 \pm 0.04$ & $84 \cdot 3$ \\
\hline$B$ & 0.083 & -.31 & $11-23 \pm(1.4) 8$ & $0.388 \pm 0.016$ & 1.61 & 0.199 & 1.54 & $172.9 \pm 9.3$ & $44 \cdot 8 \pm 2 \cdot 5$ & $0.69 \pm 0.04$ & -4.5 \\
\hline ( & 0.1885 & $8^{-7}$ & $0.1^{-} \pm 0.00^{-}$ & $(1.475 \pm(1.020)$ & 1.69 & 0.109 & 0.53 & $208 \cdot 5 \pm 9 \cdot 9$ & $57 \cdot 2 \pm 27$ & $0.81 \pm 0.05$ & 83.4 \\
\hline 1) & $0.0 \times 3$ & 10.23 & $0.12 \pm 0.06$ & (1)-581 \pm 0.024 & 1.78 & 0.11 & 0.56 & $267 \cdot 4 \pm 12 \cdot 8$ & $62-5 \pm 2-8$ & $0.83 \pm 0.015$ & 86.8 \\
\hline $\mathrm{F}$ & 1.1886 & 12.42 & $1+21 \pm 0 \cdot()^{-}$ & ()$^{-2}+ \pm(0) 31$ & 1.73 & 1.14 & 0.54 & $327.5 \pm 14^{-7}$ & $84(0 \pm 4 \cdot()$ & $0.98 \pm 0.06$ & 85.9 \\
\hline $\mathrm{r}$ & Wost & $1+62$ & $10.2+ \pm 0.10$ & (1) $-89 \pm(10)(130$ & $1 \cdot 60)$ & 0.19 & (1).56 & $32.9 \pm 15.5$ & $96 \cdot 2 \pm 41$ & $1 \cdot 2 \div \pm 0.0$ & 8.8 \\
\hline ( & 01084 & $1-5$ & $0.21 \pm 0.08$ & $0.863 \pm 0.0 .35$ & 1.54 & (1).23 & (1.59 & $414 \cdot 6 \pm 18 \cdot 2$ & $132 \cdot 4 \pm 5.7$ & $1.68 \pm 1.01$ & 81.4 \\
\hline$H_{1}=$ & 0.085 & $26)+46$ & $11.88 \pm 0.12$ & $0 \times 860 \pm 0 \cdot 0.32$ & 1.25 & 11.46 & 0.75 & $4+3 \cdot 1 \pm 18 \cdot 9$ & $1+2 \cdot 6 \pm 5 \cdot 6$ & $1.25 \pm 0.08$ & 820 \\
\hline$H H_{2}=$ & 0.085 & $20+46$ & $1.6,9 \pm 0.14$ & $(1)^{-7}+1 \pm(1)(1) 29$ & 1.34 & (1).42 & (1).89 & $411 \cdot 6 \pm 17 \cdot 6$ & $166.6 \pm 6.1$ & $1.15 \pm 0.06$ & 85.5 \\
\hline$H_{3}=$ & DAS & $2 i t+46$ & $\pm(0) \cdot \mathrm{K}$ & $(1+621 \pm 0.028$ & $1.2-$ & (1). 34 & 0.93 & $395 \pm 164$ & $16^{-4} 4 \pm 6.3$ & $0 \times 5 \pm 0.05$ & 8000 \\
\hline$H_{1}$ & OhK5 & $20+46$ & $2-14 \pm \pm(15$ & $0.733 \pm 0(0) 32$ & $1 \cdot 22$ & 0.34 & $0.4^{-}$ & $386 \cdot 4 \pm 16 \cdot 3$ & $171 \pm 6 \cdot x$ & $(1.9 .4 \pm 0.06$ & 80.6 \\
\hline s & $01-(183)$ & $1+62$ & $42+ \pm 024$ & $01+4 x^{-} \pm 0 \cdot 200$ & 1.22 & (1.37 & 10.83 & $26-8 \pm 12 \cdot 3$ & $115 \cdot 9 \pm 5 \cdot 1$ & $\mid \cdot 11 \pm 0 \cdot 0 k$ & 838 \\
\hline
\end{tabular}

$\because$ Values of parameters are shown but were not obtained under steady-state conditions.

When the cellobiose was exhausted, cell lysis was observed despite a slight consumption of pyruvate. The stationary phase occurred before cellobiose became limiting and the growth arrest could not be attributed to limitation or inhibition by fermentation products since the same culture reinoculated allowed growth of the new inoculum (data not shown). This result indicates that growth inhibition of C. cellulolyticum was not due to the appearance of inhibitory compounds in the culture medium. This was confirmed by the growth of $C$. cellulolvticum in a supernatant from a culture entering stationary phase which was centrifuged and filtered or autoclaved (data not shown).

\section{Growth of C. cellulolyticum with increasing amounts of cellobiose}

When C. cellulolyticum was grown in continuous culture at a specific growth rate $(\mu)$ of approximately $0.085 \mathrm{~h}^{-1}$ and the concentration of cellobiose in the feed medium was increased in stepwise fashion, there was an increase in cellobiose consumption (Table 1) without growth inhibition (Fig. 3). Cultures which were provided with cellobiose progressively from 5.84 to $17.57 \mathrm{mM}$ (experiments $A-G$, Table 1) utilized almost all the carbon source $(<0.26 \mathrm{mM}$ left) and the microbial population increased regularly whilst the values of $Y_{\mathrm{ATT}}$ P were almost constant (Table 2). Nevertheless, when the feed cellobiose concentration was $17.57 \mathrm{mM}$, the growth parameters $Y_{A T P}$ and $Y_{\mathrm{X}_{\mathrm{S}}}$ decreased, i.e. from 13.9 to $12.7 \mathrm{~g}$ cells (mol ATP) ${ }^{-1}$ and from 54.9 to $49.7 \mathrm{~g}$ cells (mol cellobiose) $^{-1}$ for experiments F and G, respectively, indicating that some cellobiose and hence ATP were not associated with biomass formation. The same effects were accentuated when the cellobiose concentration was increased to $20.46 \mathrm{mM}$ (experiments $\mathrm{H}_{1}-\mathrm{H}_{4}$ ). The residual cellobiose concentration increased from 0.88 to $2.77 \mathrm{mM}$ and the biomass decreased from 0.860 to

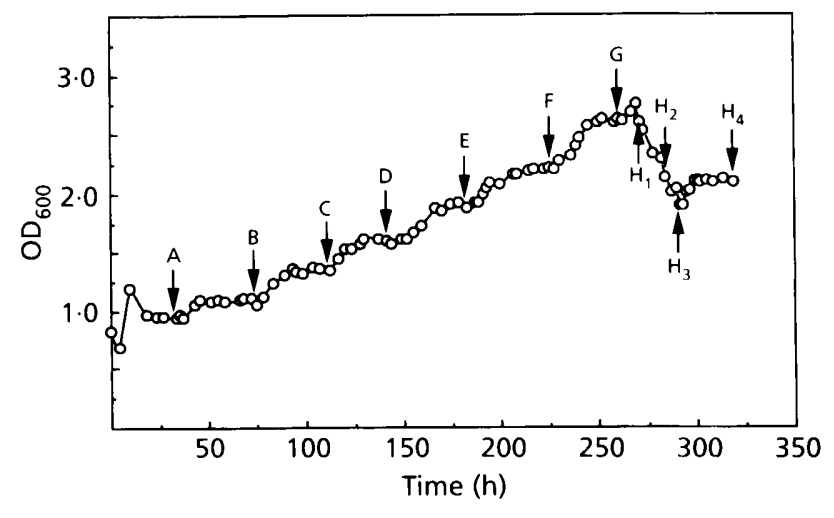

Fig. 3. Growth of $C$. cellulolyticum in continuous culture $(D=$ $\left.0.085 \pm 0.002 \mathrm{~h}^{1}\right)$ with increasing amounts of cellobiose from $5.84 \mathrm{mM}$ (experiment $A$ ) to $20.46 \mathrm{mM}$ (experiment $H$ ). The culture was sampled at the times indicated by arrows, before the addition of cellobiose concentration. Feed cellobiose (mM): A, 5.84; B, 7.31; C, 8.77; D, 10.23; E, 12.42; F, 14.62; G, 17.57; $\mathrm{H}_{1}-\mathrm{H}_{2}-\mathrm{H}_{3}-\mathrm{H}_{4}, 20.46$. Data from these experiments are summarized in Tables 1, 2 and 3.

$0.621 \mathrm{~g} \mathrm{l}^{-1}$ (steps $\mathrm{H}_{1}, \mathrm{H}_{2}, \mathrm{H}_{3}$ ); the steady state was recovered only in step $\mathrm{H}_{4}$, and $Y_{\mathrm{X} / \mathrm{s}}\left(39 \cdot 8{\left.\mathrm{~g} \mathrm{cells} \mathrm{mol}^{-1}\right)}^{-1}\right.$ and $Y_{\text {ATP }}\left(10 \cdot 7 \mathrm{~g}\right.$ cells $\left.\mathrm{mol}^{-1}\right)$ decreased sharply. These results indicate that (i) experiments $A-G$ were performed under conditions of cellobiose limitation, (ii) increased carbon flow from 1.46 to 1.69 mmol cellobiose (g cells $)^{-1} \mathrm{~h}^{-1}$ was balanced by the demands for biosynthesis, (iii) the increase of $q_{\text {cellotiose }}$ above 1.69 mmol $(\mathrm{g} \text { cells })^{-1} \mathrm{~h}^{-1}$ led to substrate-sufficient cultures with imbalance between cellobiose uptake and the demands for biosynthesis.

When the reactor was fed directly with $14.62 \mathrm{mM}$ cellobiose in experiment $\mathrm{S}$, compared with experiment $\mathrm{G}(17.57 \mathrm{mM}$ cellobiose), the residual cellobiose con- 
Table 2. Specific consumption and production rates for the continuous cultures of Table 1

For experiments $\mathrm{A}-\mathrm{H}_{1}$, cultures were provided with cellobiose in increasing amounts from 5.84 to $20.46 \mathrm{mM}$ (see Fig. 3 legend). In the experiments $S$, the reactor was fed directly with $14.62 \mathrm{mM}$ cellobiose. Values represent mean determinations from three different samples $( \pm \mathrm{SD})$. All other values were determined with a mean accuracy of $10 \%$.

\begin{tabular}{|c|c|c|c|c|c|c|c|c|}
\hline \multirow[t]{2}{*}{ Experiments } & \multirow[t]{2}{*}{$\begin{array}{c}D \\
(\mathbf{h} 1)\end{array}$} & \multicolumn{4}{|c|}{$\begin{array}{l}\text { Specific rate of cellobiose consumption or product formation } \\
{\left[\left[\mathrm{mmol}^{(\mathrm{g} \text { cells) }}{ }^{2} h{ }^{\prime}\right]\right.}\end{array}$} & \multirow[t]{2}{*}{$\begin{array}{l}\text { Extracellular } q_{\text {prruvate }} \\
{\left[\mu \mathrm{mol} \text { (g cells) }{ }^{i} \mathbf{h} \text { i] }\right.}\end{array}$} & \multirow[t]{2}{*}{$\underset{\left[(\mathrm{g} \text { cells })^{\mathrm{ATP}} \mathrm{mol}\right.}{\left.\mathbf{m o l}^{\prime}\right]}$} & \multirow[t]{2}{*}{$\begin{array}{c}Y_{x}, \\
{[(g \text { cells }) \text { mol ' }}\end{array}$} \\
\hline & & $q_{\text {cellobuse }}$ & $q_{\text {scetale }}$ & $q_{\text {|actate }}$ & $\boldsymbol{q}_{\text {sthanol }}$ & & & \\
\hline A & 0.086 & 1.46 & $2 \cdot 49$ & 0.14 & 0.78 & 38.6 & 14.5 & 58.0 \\
\hline B & 0.08 .3 & 1.51 & 2.44 & $0 \cdot 1.3$ & 0.82 & $37 \cdot 0$ & $14 \cdot 2$ & $54 \cdot 8$ \\
\hline C & 0.085 & 1.54 & 2.61 & 0.14 & 0.82 & $37 \cdot 3$ & 13.7 & $55 \cdot 2$ \\
\hline $\mathrm{D}$ & 0.083 & 1.44 & 2.57 & 0.15 & 0.81 & 38.2 & $13 \cdot 6$ & 57.5 \\
\hline $\mathrm{E}$ & 0.086 & 1.45 & 2.51 & 0.21 & 0.79 & $38 \cdot 9$ & $14: 3$ & 59.3 \\
\hline $\mathrm{F}$ & 0.084 & 1.53 & 2.45 & 0.26 & 0.86 & $39 \cdot 7$ & 13.9 & $54 \cdot 9$ \\
\hline G & 0.084 & 1.69 & $2 \cdot 60$ & 0.35 & 1.00 & $40 \cdot 3$ & 12.7 & 49.7 \\
\hline $\mathrm{H}_{1}^{*}$ & 0.085 & 1.94 & $2 \cdot 41$ & 0.90 & 1.45 & $43 \cdot 6$ & 11.8 & 43.9 \\
\hline $\mathrm{H}_{3} "$ & 0.08 .5 & $2 \cdot 15$ & $2 \cdot 88$ & 0.91 & 1.91 & $47 \cdot 2$ & $10 \cdot 1$ & 34.5 \\
\hline $\mathrm{H}_{3}{ }^{k}$ & 0.085 & $2 \cdot 42$ & 3.09 & 0.83 & $2 \cdot 24$ & $54 \cdot 1$ & 8.9 & $35 \cdot 1$ \\
\hline $\mathrm{H}_{4}$ & 0.085 & $2 \cdot 13$ & 2.62 & 0.73 & 1.99 & $44 \cdot 8$ & 10.7 & $39 \cdot 8$ \\
\hline$S^{+}$ & 0.08 .3 & 1.77 & $2 \cdot 15$ & 0.65 & 1.46 & $45 \cdot 6$ & $12 \cdot 9$ & 46.9 \\
\hline
\end{tabular}

*Values of parameters are shown but were not obtained under steady-state conditions.

Table 3. Oxidoreduction balance, nucleotide levels and electron flow for the continuous cultures of Table 1

For experiments $\mathrm{A}-\mathrm{H}_{1}$, cultures were provided with cellobiose in increasing amounts from 5.84 to $20 \cdot 46 \mathrm{mM}$ (see Fig. 3 legend). In the experiments $S$, the reactor was fed directly with $14.62 \mathrm{mM}$ cellobiose. Values represent mean determinations from three different samples $( \pm S D)$. All other values were determined with a mean accuracy of $10 \%$.

\begin{tabular}{|c|c|c|c|c|c|c|c|c|c|c|c|}
\hline \multirow[t]{2}{*}{ Experiments } & \multirow{2}{*}{$\begin{array}{c}D \\
\left(h^{\prime}\right)\end{array}$} & \multirow{2}{*}{$\begin{array}{l}\mathrm{H}_{2}[\mathrm{~mol} \text { (mol } \\
\text { cellobiose) '] }\end{array}$} & \multirow{2}{*}{$\begin{array}{l}\mathrm{CO}_{2}[\mathrm{~mol}(\mathrm{~mol} \\
\text { cellobiose) '] }\end{array}$} & \multirow[t]{2}{*}{$\mathrm{H}_{2} / \mathrm{CO}_{2}$} & \multirow[t]{2}{*}{$\mathrm{O} / \mathrm{R}$ index } & \multicolumn{4}{|c|}{ Intracellular nucleotide ( $\mu \mathrm{mol}$ (g cells) IJ } & \multirow{2}{*}{$\begin{array}{l}\mathcal{q}_{\text {hydrimen }} \mid \mathrm{mmol} \\
\text { (g cells) 'h }{ }^{1} \mid\end{array}$} & \multirow{2}{*}{$\begin{array}{c}q_{\mathrm{NAIH}} \text { produced } \\
/_{\mathrm{NAIHH}} \text { used }\end{array}$} \\
\hline & & & & & & $\mathrm{NADH}$ & NADPH & $\mathrm{NAD}^{+}$ & NADP $^{+}$ & & \\
\hline A & 0.086 & $3 \cdot 54$ & $2 \cdot 34$ & 1.51 & $1 \cdot 02$ & $5 \cdot 3 \pm 0 \cdot 9$ & $3 \cdot 2 \pm 0.5$ & $17 \cdot 1 \pm 3 \cdot 7$ & ND) & $1 \cdot 70$ & 1.99 \\
\hline B & 0.08 .3 & $3 \cdot 04$ & 2.00 & 1.52 & 0.97 & $5 \cdot 9 \pm 0.8$ & $3 \cdot 8 \pm 0 \cdot 4$ & $16 \cdot 3 \pm 3 \cdot 5$ & $\mathrm{ND}$ & 1.62 & 1.41 \\
\hline C & 0.085 & 3.54 & $2 \cdot 30$ & 1.54 & 1.00 & $6.4 \pm 1 \cdot 2$ & $3.6 \pm 0.5$ & $17 \cdot 3 \pm 3.6$ & ND) & 1.79 & 2.01 \\
\hline $\mathrm{D}$ & 0.083 & 3.72 & $2 \cdot 43$ & 1.53 & 1.00 & $7 \cdot 0 \pm 1 \cdot 2$ & $3.6 \pm 0.4$ & $17 \cdot 2 \pm 3 \cdot 4$ & $0.06 \pm 0.01$ & 1.77 & $2 \cdot(6)$ \\
\hline E. & 0.086 & 3.41 & $2 \cdot 20$ & 1.55 & 0.98 & $6 \cdot 2 \pm 1 \cdot 1$ & $3 \cdot 4 \pm 0.4$ & $15 \cdot 5 \pm 3 \cdot 2$ & $0.06 \pm 0.01$ & 1.72 & 1.96 \\
\hline $\mathrm{F}$ & 0.084 & 3.43 & $2 \cdot 23$ & 1.54 & 0.98 & $6.9 \pm 1.5$ & $3.8 \pm 0.5$ & $17.7 \pm 3.5$ & $0 \cdot 04 \pm(0 \cdot 01$ & 1.59 & 1.81 \\
\hline G & 0.084 & 3.14 & 2.08 & 1.51 & 0.96 & $6.9 \pm 1.3$ & $3 \cdot 7 \pm 0.4$ & $16 \cdot 1 \pm 3 \cdot 1$ & $0.06 \pm 0.01$ & 1.59 & 1.68 \\
\hline $\mathrm{H}_{1}{ }^{*}$ & 0.085 & 2.86 & 2.06 & 1.39 & 0.94 & $7 \cdot 3 \pm 1.8$ & $3 \cdot 3 \pm 0.4$ & $13 \cdot 6 \pm 2.9$ & $0.08 \pm(0.01$ & 0.96 & 1.25 \\
\hline $\mathrm{H}_{2}{ }^{*}$ & 0.085 & 2.90 & $2 \cdot 28$ & 1.27 & 0.98 & $8.8 \pm 1.7$ & $3.5 \pm 0.5$ & $12.5 \pm 2.6$ & $0-06 \pm 0-01$ & 0.96 & $1 \cdot 21$ \\
\hline $\mathrm{H}_{3}{ }^{2}$ & 0.085 & 2.52 & $2 \cdot 14$ & $1 \cdot 18$ & 0.98 & $8.9 \pm 1.9$ & $3 \cdot 3 \pm 0.4$ & $16 \cdot 3 \pm 3 \cdot 2$ & $0.07 \pm(1-01$ & 0.85 & $1 \cdot 16$ \\
\hline $\mathrm{H}_{4}$ & 0.08 .5 & $2 \cdot 33$ & $2 \cdot 09$ & $1 \cdot 11$ & 1.00 & $7 \cdot 3 \pm 1.7$ & $3.6 \pm 0.5$ & $12 \cdot 2 \pm 2 \cdot 6$ & $0.06 \pm 0.01$ & 0.63 & $1 \cdot 13$ \\
\hline$s$ & 0.083 & $2 \cdot 43$ & 1.98 & 1.23 & 0.97 & $7 \cdot 2 \pm 1 \cdot 2$ & $3.4 \pm 0.5$ & $10 \cdot 6 \pm 2 \cdot 9$ & ND & 0.69 & $1 \cdot 19$ \\
\hline
\end{tabular}

ND, Not detectable.

*Values of parameters are shown but were not obtained under steady-state conditions.

centration increased and the biomass decreased $(38.3 \%)$. This comparison indicated that the cells were not able to regulate high carbon flow and that the growth inhibition observed in experiment $S$ was not due to end-product toxicity since end-product concentrations were higher in experiment $F$ (Table 1). C. cellulolyticum may have been unable to regulate the cellobiose uptake and growth inhibition may have been due to an inability of bacteria to deal with high concentrations of carbon compounds internally.

Extracellular pyruvate was observed in all experiments (Table 1), suggesting that the flow through the pyruvate: fd oxidoreductase was limiting. An increase in pyruvate concentration correlated with accumulation of extracellular protein and biomass. The global carbon balance, calculated by taking into account cellobiose consumption converted into biomass, products, amino acids and peptides, was in the range $79 \cdot 5-86.8 \%$ (Table $1)$. The specific rates of acetate, lactate, pyruvate and ethanol formation were almost stable during experiments A-G (Table 2 ), except that $q_{\text {lactate }}$ and $q_{\text {ethanol }}$ increased in experiments $E-G$ and $F-G$, respectively. Their specific production rate increased sharply when cellobiose was present in excess (experiments $\mathrm{H}_{4}$ and $S$ ), whereas $q_{\text {acetate }}$ and $q_{\text {pyruvate }}$ remained nearly constant.

\section{Redox balance}

For the chemostats carried out under carbon limitation, the coenzyme balance (Table 3) calculated from the known catabolic pathways producing or consuming 


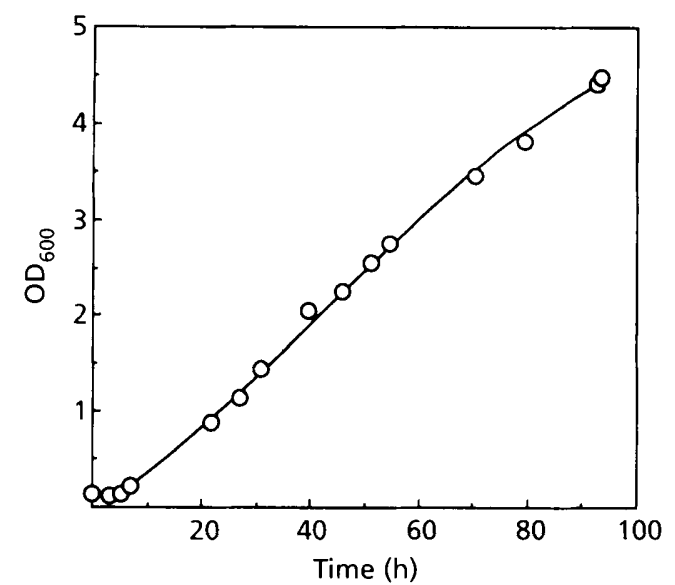

Fig. 4. Growth of C. cellulolyticum in dialysis tubing.

reducing equivalents demonstrate an excess of $\mathrm{NADH}$ since the ratio $q_{\mathrm{NADH}}$ produced $/ q_{\mathrm{NADH}}$ used was always greater than 1 (experiments $A-G$, Table 3). This result correlated with ratios of $\mathrm{H}_{2} / \mathrm{CO}_{2}$ greater than 1 obtained by measuring $\mathrm{CO}_{2}$ and $\mathrm{H}_{2}$ evolved. These ratios suggest that $H_{2}$ was produced via $N A D H: f d$ reductase and hydrogenase activities in addition to the phosphoroclastic reaction, which produces $1 \mathrm{~mol} \mathrm{CO}_{2}$ and $1 \mathrm{~mol} \mathrm{H}_{2}$ (mol pyruvate) ${ }^{-1}$ catabolized (Mortenson et al., 1963). When chemostat cultures were incubated with excess cellobiose, the main effect was an increase in the specific rates of lactate and ethanol production: the $q_{\text {lactate }}$ and $q_{\text {ethanol }}$ increased by a factor of 2 and the $\mathrm{H}_{2} / \mathrm{CO}_{2}$ ratios decreased from 1.5 to $1 \cdot 1-1 \cdot 2$ (experiments $\mathrm{H}_{4}$ and $S$ ).

The low values of $q_{\text {lat }}$ ate and $q_{\text {ethanol }}$ under conditions of cellobiose limitation (experiments $A-G$ ) apparently were not sufficient to regenerate the $\mathrm{NAD}^{+}$from $\mathrm{NADH}$, so the production of $\mathrm{H}_{2}$ via NADH-fd- $\mathrm{H}_{2}$ with $q_{\mathrm{NAIH}}$ id from 1.59 to 1.79 mmol (g cells) ${ }^{-1} \mathrm{~h}^{-1}$ (Table 3) was more significant in these culture conditions than under cellobiose excess (experiments $\mathrm{H}_{1}-\mathrm{H}_{4}$ and S).

Taking into account the production of hydrogen gas, ethanol and lactate, the $\mathrm{O} / \mathrm{R}$ index was determined to be around 1 . The nucleotide levels did not vary significantly among cellobiose-sufficient or excess cultures, $\mathrm{NADP}^{+}$was not or almost not detectable, whereas the NADPH levels were remarkably constant (Table 3 ). NADH ranged from 5.3 to $7.3 \mu \mathrm{mol}$ (g cells) ${ }^{-1}$ and $\mathrm{NAD}^{+}$from 10.6 to $17.7 \mu \mathrm{mol}$ (g cells) ${ }^{-1}$, indicating an efficient regeneration of $\mathrm{NAD}^{+}$from $\mathrm{NADH}$.

\section{Dialysis culture}

C. cellulolyticum was grown in dialysis culture on mineral medium with $23.4 \mathrm{mM}$ cellobiose as described by Gehin et al. (1996) (Fig. 4). A linear growth curve was observed with a maximum generation time of $4 \mathrm{~h}$, which correlated with the value found in batch culture $(3 \cdot 8 \mathrm{~h})$. It is likely that cellobiose diffusion limited growth since this compound was not detected inside the dialysis tubing. This may have led to a decrease in the carbon flow, and enabled an increase of the biomass formation by a factor of 3 to occur.

\section{DISCUSSION}

Previous work indicated that growth of C. cellulolyticum in chemostat cultures on complex medium was limited by an imbalance in the specific rate of $\mathrm{NADH}$ production and the specific rate of NADH consumption, leading to $\mathrm{NADH} / \mathrm{NAD}^{+}$ratios as high as 57 and intracellular NADH concentrations ranging from 3 to $40 \mu \mathrm{mol}$ (g cell mass) ${ }^{-1}$ (Payot et al., 1998). It was concluded that high intracellular concentrations of $\mathrm{NADH}$ detected in complex medium revealed a low rate of NADH reoxidation (Holms, 1996) and that the production of lactate, ethanol and hydrogen via NADHfd $-\mathrm{H}_{2}$ was rate limiting. Due to a low rate of NADH reoxidation, the cells probably maintain a sufficient $\mathrm{NAD}^{+}$pool size available for cellobiose catabolism.

This study shows that changing the growth condition from complex medium to synthetic medium had a strong effect on the electron flow since the NADH produced by glycolysis was well balanced by the production of hydrogen gas, ethanol and lactate, leading to $\mathrm{NADH} / \mathrm{NAD}^{+}$ratios in the range of $0 \cdot 3-0 \cdot 7$. This interpretation was supported by the results of our study on the effect of carbon flow in C. cellulolyticum grown in chemostat culture on synthetic medium. At low $D$ values high $\mathrm{H}_{2} / \mathrm{CO}_{2}$ and $\mathrm{NADH} / \mathrm{NAD}^{+}$ratios were observed, coinciding with low $q_{\text {lartate }}$ and $q_{\text {ethanol }}$ values and low in vitro lactate and ethanol dehydrogenase activities. In contrast, at high $D$ values the $\mathrm{H}_{2} / \mathrm{CO}_{2}$ and $\mathrm{NADH} / \mathrm{NAD}^{+}$ratios decreased sharply, whereas the $q_{\text {lactate }}$ and $q_{\text {ethanol }}$ values and in vitro lactate and ethanol dehydrogenase activities increased (data not shown).

Compared with growth on complex medium, the specific production rates of ethanol and lactate were both increased about 10-fold during growth on synthetic medium. Clearly, these data indicate a better control of the electron flow by C. cellulolyticum, i.e. low NADH/ $\mathrm{NAD}^{+}$ratios with lactate and ethanol production complementing hydrogen via NADH $-\mathrm{fd}-\mathrm{H}_{2}$.

In addition to a better regulation of the redox balance in cells grown in synthetic medium explaining higher specific cellobiose consumption in this medium, it is necessary to take into consideration the fact that, on complex medium, yeast extract supplies many cell constituents and cellobiose serves mainly as an energy supply, whereas on mineral salts medium, a mean value of $60 \%$ of the cellobiose consumed was converted into end products of fermentation and the rest into biomass and extracellular proteins and amino acids.

Nevertheless, the rate of cellobiose catabolism apparently exceeded the rate of pyruvate consumption, since pyruvate accumulated. This suggests that, in C. cellulolyticum, pyruvate consumption via pyruvate fd-oxido- 
reductase is a rate-limiting step. When carbon flow was limited either by cellobiose diffusion through the dialysis tubing or by continuous culture under cellobiose limitation, no growth inhibition was observed. It may thus be concluded that growth inhibition was directly related to an inefficiently regulated carbon flow. This interpretation was supported by the results of studies of growth in cellobiose batch cultures, in which growth arrest was not due to nutritional limitation or inhibition by fermentation products since new cells reinoculated in the same culture were able to grow. The growth arrest of the first seeding could be explained by a carbon flow which leads to an accumulation of intracellular inhibitory compounds. Due to early inhibition of metabolism, the accelerating growth phase was rapidly followed by the decelerating growth phase and a $\mu_{\max }$ of $0 \cdot 18 \mathrm{~h}^{-1}$ could not be maintained (Fig. 2). In view of these considerations, it can be argued that C. cellulolyticum is not adapted to use carbon source and other nutrients in excess since, on complex medium, cells were not able to induce high specific rates of ethanol and lactate production. Indeed, natural ecosystems where cellulolytic microbes proliferate rarely contain all nutrients in saturating quantities, particularly a carbon source derived from cellulose. This insoluble substrate is usually coated by other polymers, predominantly xylan and lignin, which may hinder cellulolysis and hence reduce carbon availability.

It has been found that many bacteria isolated from oligotrophic reservoirs acquire the ability spontaneously or by adaptation to develop on rich media (Kuznetsov $e t$ al., 1979). However, this is not the case with $C$. cellulolyticum or with cellulolytic bacteria as a rule (Sleat et al., 1984; Cailliez et al., 1992; Tomme et al., 1995). It is reasonable to suppose that during the course of C. cellulolyticum evolution, these bacteria have evolved to optimize catabolism of poorly available carbon sources. The results of this study suggest that $C$. cellulolyticum is adapted to life at low nutrient concentrations.

\section{ACKNOWLEDGEMENTS}

This work was supported by the Commission of European Communities FAIR programme [contract no. CT 95-0191 (DG 12 SSMA)] and by the programme Agrice (no. 9701041). The authors thank Michel Mercy of Laboratoire de Catalyse Hétérogène for his technical assistance.

\section{REFERENCES}

Bradford, M. M. (1976). A rapid and sensitive method for the quantitation of microgram quantities of protein utilizing the principle of protein-dye binding. Anal Biochem 72, 248-254.

Bryant, M. P. (1972). Commentary on the Hungate technique for culture of anaerobic bacteria. Am J Clin Nutr 25, 1324-1328.

Cailliez, C., Benoit, L., Thirion, J.-P. \& Petitdemange, H. (1992). Characterization of 10 mesophilic cellulolytic clostridia isolated from a municipal solid waste digestor. Curr Microbiol 25, $105-112$.

Gehin, A., Gelhaye, E., Raval, G. \& Petitdemange, H. (1995).
Clostridium cellulolyticum viability and sporulation under cellobiose starvation conditions. Appl Environ Microbiol 61, 868-871.

Gehin, A., Cailliez, C., Petitdemange, E. \& Benoit, L. (1996). Studies of Clostridium cellulolyticum ATCC 35319 under dialysis and co-culture conditions. Lett Appl Microbiol 23, 208-212.

Gelhaye, E., Gehin, A. \& Petitdemange, H. (1993a). Colonization of crystalline cellulose by Clostridium cellulolyticum ATCC 35319. Appl Environ Microbiol 59, 3154-3156.

Gelhaye, E., Petitdemange, H. \& Gay, R. (1993b). Adhesion and growth rate of Clostridium cellulolyticum ATCC 35319 on crystalline cellulose. J Bacteriol 175, 3452-3458.

Giallo, J., Gaudin, C., Belaich, J.-P., Petitdemange, E. \& CailletMangin, F. (1983). Metabolism of glucose and cellobiose by cellulolytic mesophilic Clostridium sp. strain H10. Appl Environ Microbiol 45, 843-849.

Gottschalk, G. (1985). Bacterial Metabolism, 2nd edn. New York/Heidelberg/Berlin: Springer.

Holms, H. (1996). Flux analysis and control of the central metabolic pathways in Escherichia coli. FEMS Microbiol Rev 19, 85-116.

Hungate, R. E. (1969). A roll tube method for cultivation of strict anaerobes. Methods Microbiol 33, 117-132.

Klingenberg, M. (1965). Nicotinamide-adenine dinucleotides $\left(\mathrm{NAD}^{+}, \mathrm{NADP}^{+}, \mathrm{NADH}, \mathrm{NADPH}\right)$. Spectrophotometric and fluorimetric methods. In Methods in Enzymatic Analysis, pp. 2045-2059. Edited by H. Y. Bergmeyer. New York: Academic Press.

Koch, A. L. (1997). Microbial physiology and ecology of slow growth. Microbiol Mol Biol Rev 61, 305-318.

Kuznetsov, S. I., Dubinina, G. A. \& Lapteva, N. A. (1979). Biology of oligotrophic bacteria. Annu Rev Microbiol 33, 377-387.

Leschine, S. B. (1995). Cellulose degradation in anaerobic environments. Annu Rev Microbiol 49, 399-426.

London, J. \& Knight, M. (1966). Concentrations of nicotinamide nucleotide coenzymes in micro-organisms. J Gen Microbiol 44, 241-254.

Miller, G. L. (1959). Use of dinitrosalicylic acid reagent for determination of reducing sugars. Anal Chem 31, 426-428.

Mokrasch, L. C. (1967). Use of 2,4,6-trinitrobenzenesulfonic acid for the coestimation of amines, amino acids and proteins in mixtures. Anal Biochem 18, 64-71.

Mortenson, L. E., Valentine, R. C. \& Carnahan, J. E. (1963). Ferredoxin in the phosphoroclastic reaction of pyruvic acid and its relation to nitrogen fixation in Clostridium pasteurianum. J Biol Chem 238, 794-800.

Payot, S., Guedon, E., Cailliez, C., Gelhaye, E. \& Petitdemange, H. (1998). Metabolism of cellobiose by Clostridium cellulolyticum growing in continuous culture: evidence for decreased $\mathrm{NADH}$ reoxidation as a factor limiting growth. Microbiology 144, 375-384.

Petitdemange, E., Caillet, F., Giallo, J. \& Gaudin, C. (1984). Clostridium cellulolyticum sp. nov., a cellulolytic mesophilic species from decayed grass. Int J Syst Bacteriol 34, 155-159.

Sleat, R., Mah, R. \& Robinson, R. (1984). Isolation and characterization of an anaerobic, cellulolytic bacterium, Clostridium cellulovorans sp. nov. Appl Environ Microbiol 48, 88-93.

Tomme, P., Warren, R. A. J. \& Gilkes, N. R. (1995). Cellulose hydrolysis by bacteria and fungi. Adv Microbiol Physiol 37, 1-81.

Vasconcelos, I., Girbal, L. \& Soucaille, P. (1994). Regulation of carbon and electron flux in Clostridium acetobutylicum grown in 
chemostat culture at neutral pH on mixture of glucose and glycerol. J Bacteriol 176, 1443-1450.

Weimer, P. J. \& Zeikus, J. G. (1977). Fermentation of cellulose and cellobiose by Clostridium thermocellum in the absence and presence of Methanobacterium thermoautotrophicum. Appl Environ Microbiol 33, 289-297.

Wimpenny, J. W. T. \& Firth, A. (1972). Levels of nicotinamide adenine dinucleotide and reduced nicotinamide adenine dinucleotide in facultative bacteria and the effect of oxygen. J Bacteriol 111, 24-32.

Received 2 February 1999; revised 31 March 1999; accepted 30 April 1999. 